\title{
Post-COVID-19 Dysphonia may have Several Origins
}

\author{
Jerome R. Lechien ${ }^{1,2,3} \cdot$ Sven Saussez ${ }^{1,3} \cdot$ Luigi A. Vaira $^{4} \cdot$ Stephane Hans $^{2}$
}

Received: 2 July 2021/ Accepted: 16 October 2021/Published online: 28 October 2021

(C) Association of Otolaryngologists of India 2021

Keywords Dysphonia $\cdot$ COVID-19 $\cdot$ SARS-CoV-2 . Voice $\cdot$ Infection $\cdot$ Reflux

\section{Dear Editor}

We read the article entitled: "Vocal Disorders in Patients with COVID 19 in Egypt" by Aziz Azzam et al. [1]. The authors investigated the occurrence of dysphonia in COVID-19 patients in Egypt and the videolaryngoscopic findings associated with vocal symptoms. They reported that $79 \%$ of patients had dysphonia, while $18.8 \%$ were phonesthenic. Authors observed a significant association between rhinorrhea, sore throat, cough and dysphonia. At the videolaryngostroboscopical examination, they found vocal fold edema, swellings, ventricular hypertrophy and vocal fold immobility. Vocal fold congestion was associated with dysphonia. The study of dysphonia in COVID-19 patients is important and we congratulate authors for this

Jerome R. Lechien

Jerome.Lechien@umons.ac.be

1 Laboratory of Anatomy and Cell Biology, Faculty of Medicine, University of Mons (UMONS), Avenue du Champ de mars, 6, B7000 Mons, Belgium

2 Department of Otorhinolaryngology-Head \& Neck Surgery, Foch Hospital, Paris Saclay University, Paris, France

3 Department of Otorhinolaryngology, Elsan Hospital, Paris, France

4 Maxillofacial Surgery Operative Unit, Department of Medical, Surgical and Experimental Sciences, University of Sassari, Sassari, Italy research. However, we wish to draw attention to many points.

First, as reported in other studies [2, 3], COVID-19 may be associated with dysphonia and the study of Aziz Azzam et al. supports the association. An important confounding factor that was not evaluated by authors is the prevalence of laryngopharyngeal reflux (LPR) in the cohort. The prevalence of LPR in North Africa was estimated to $19.2 \%$ [4]. LPR is associated with similar otolaryngological nonspecific symptoms than COVID-19, including cough, postnasal drip, throat clearing, throat pain, and dysphonia [4]. From a clinical standpoint, LPR is associated with vocal fold findings, swelling, ventricular and laryngeal edema [4]; all of them being observed by Aziz Azzam et al. in the study population. The consideration of LPR is important in a pandemic period because the increased stress and anxiety of patient related to COVID-19 infection may have favored autonomic nerve dysfunction, which is associated with esophageal sphincter relaxations and, therefore, an increase of pharyngeal reflux events [5]. Interestingly, females are more susceptible to develop dysphonia related to LPR [6], which may corroborate the observation of Aziz Azzam et al. The increase of LPR prevalence in the context of COVID-19 pandemic was moreover suggested in a previous study [7].

Second, the use of inhaled corticosteroids is another confounding factor that may be associated with dysphonia. Inhaled corticosteroids may be particularly prescribed in patients with mild COVID-19 and dyspnea. The consideration of inhaled corticosteroids makes sense because they may lead to vocal fold dryness and dysphonia [8].

Third, authors observed vocal fold immobility in $13.2 \%$ of patients. This observation is particularly important because severe acute respiratory syndrome coronavirus 2 (SARS-CoV-2) is known to be a neurotropic virus, and was 
associated with some nerve disorders, i.e. vocal fold paradoxical movement, olfactory dysfunction, and sudden hearing loss [9, 10]. The prevalence of laryngeal nerve impairments in COVID-19 population is probably underestimated because, in practice, few dysphonic patients really benefited from videolaryngostroboscopical examination. This association has to be investigated in future large multicenter studies.

We congratulate Aziz Azzam et al. for this interesting study that highlights the importance of dysphonia in COVID-19. Future studies are needed to reinforce the prevalence of dysphonia in COVID-19 patients considering direct and indirect mechanisms such as LPR or inhaled corticosteroids.

Funding No funding.

\section{Declarations}

Conflict of interest The authors declare that they do not have any conflict of interest.

\section{References}

1. Azzam AAA, Samy A, Sefein I, ElRouby I (2021) Vocal Disorders in Patients with COVID 19 in Egypt. Indian J Otolaryngol Head Neck Surg. https://doi.org/10.1007/ s12070-021-02663-0

2. Cantarella G, Aldè M, Consonni D, Zuccotti G, Berardino FD, Barozzi S, Bertoli S, Battezzati A, Zanetti D, Pignataro L (2021) Prevalence of Dysphonia in Non hospitalized Patients with COVID-19 in Lombardy, the Italian Epicenter of the Pandemic. J Voice S0892-1997(21):00108-00109. https://doi.org/10.1016/ j.jvoice.2021.03.009

3. Lechien JR, Chiesa-Estomba CM, Cabaraux P, Mat Q, Huet K, Harmegnies B et al (2020) Features of Mild-to-Moderate
COVID-19 Patients With Dysphonia. J Voice S0892-1997 (20):30183-30191. https://doi.org/10.1016/j.jvoice.2020.05.012

4. Lechien JR, Allen JE, Barillari MR, Karkos PD, Jia H, Ceccon FP, Imamura R, Metwaly O, Chiesa-Estomba CM, Bock JM, Carroll TL, Saussez S, Akst LM (2021) Management of Laryngopharyngeal Reflux Around the World: An International Study. Laryngoscope 131(5):E1589-E1597. https://doi.org/10.1002/lary. 29270

5. Wang AM, Wang G, Huang N, Zheng YY, Yang F, Qiu X, Chen XM (2019) Association between laryngopharyngeal reflux disease and autonomic nerve dysfunction. Eur Arch Otorhinolaryngol 276(8):2283-2287. https://doi.org/10.1007/s00405-01 9-05482-w

6. Lechien JR, Huet K, Khalife M, Fourneau AF, Finck C, Delvaux V, Piccaluga M, Harmegnies B, Saussez S (2018) Gender differences in the presentation of dysphonia related to laryngopharyngeal reflux disease: a case-control study. Eur Arch Otorhinolaryngol 275(6):1513-1524. https://doi.org/10.1007/ s00405-018-4951-2

7. Jiang G, Cai Y, Yi X, Li Y, Lin Y, Li Q, Xu J, Ke M, Xue K (2020) The impact of laryngopharyngeal reflux disease on 95 hospitalized patients with COVID-19 in Wuhan, China: A retrospective study. J Med Virol 92(10):2124-2129. https://doi.org/ 10.1002/jmv. 25998

8. Spantideas N, Drosou E, Bougea A, Assimakopoulos D (2017) Inhaled Corticosteroids and Voice Problems What Is New? J Voice. 31(3):384e1-384e7. https://doi.org/10.1016/j.jvoice. 2016.09.002

9. Lechien JR, Circiu MP, Crevier-Buchman L, Hans S (2021) PostCOVID-19 paradoxical vocal fold movement disorder. Eur Arch Otorhinolaryngol 278(3):845-846. https://doi.org/10.1007/s004 05-020-06391-z

10. Kilic O, Kalcioglu MT, Cag Y, Tuysuz O, Pektas E, Caskurlu H, Cetın F (2020) Could sudden sensorineural hearing loss be the sole manifestation of COVID-19? An investigation into SARSCOV-2 in the etiology of sudden sensorineural hearing loss. Int J Infect Dis 97:208-211. https://doi.org/10.1016/j.ijid.2020.06.023

Publisher's Note Springer Nature remains neutral with regard to jurisdictional claims in published maps and institutional affiliations. 